\title{
Glacial fluctuations and its impacts on lakes in the southern Tibetan Plateau
}

\author{
YAO TanDong \\ Key Laboratory of Tibetan Environment Changes \& Land Surface Processes, Institute of Tibetan Plateau Research, Chinese Academy of Sciences, \\ Beijing 100085, China
}

Most of the glacial mass on the Tibetan Plateau and the surrounding regions is in the mid- and low-latitudes. According to China's latest glacier inventory, there are about 36793 existing glaciers with a total area of roughly $49873.44 \mathrm{~km}^{2}$ on the Tibetan Plateau, accounting for about $79.5 \%$ of the total glaciers and $84 \%$ of the total glacial area in China. Glaciers on the Tibetan Plateau can be categorized into three types: marine-type glaciers (or temperate glaciers); sub-continental glaciers (or sub-polar glaciers); and continental glaciers (i.e. polar glaciers).

Since global warming accelerated in the 1980s, glaciers on the Tibetan Plateau have been experiencing a negative mass balance state. Glacial retreat has been changing from rapid retreat to an accelerating retreat. However, glacial retreat on the Tibetan Plateau demonstrates apparent regional differences, with glacier retreat magnitudes increasing from the inland areas to the margins of the plateau. The smallest retreat magnitudes are inland, with the largest in the southeastern Tibetan Plateau, particularly the northern slope of Mt. Qomolangma, and the Karakorum Mountains.

During this time of global change, glacial retreat in the past few decades has severely affected river discharge originating from the Tibetan Plateau, increasing the instability of glacial melt-fed rivers. Thus, with continuing glacial retreat, the amount of glacial melt water would likely decrease with decreasing glacial area, seriously influencing glacial melt-fed rivers.

It is growing increasingly apparent that glacial retreat is also leading to rising levels and expanding areas of glacial melt-fed lakes. Consequently, pastures may become flooded, impacting regional ecosystems and the environment, as well as the daily life of the local people. This is particularly evident in the lake basins on the plateau of Nairiping Co, Dong Co, Peng Co, and Bamu Co.

Glacial retreat causes natural hazards. The accelerating glacial retreat is increasing the intensity and frequency of glacial lake outburst floods, debris flows and landslides. It has also brought about ecological issues such as the deterioration of glacial tourism resources, degradation of grassland, and water resource problems. These issues greatly hinder the adaptability of the Tibetan Plateau environment, thus further obstructing harmonious development of the economy and the environment.

Unfortunately, the study of glaciers on the Tibetan Plateau has been limited because of the harsh natural conditions there. Thanks to the support of the National Natural Science Foundation of China (NSFC), Chinese scientists have recently had the opportunity to focus on the study of the glaciers in the southeastern Tibetan Plateau, producing valuable data and proposing new insights into the understanding of glacial fluctuations and their impacts. In particular, 5 research papers within this issue of Chinese Science Bulletin, under the auspices of the NSFC key regional/ international cooperation program entitled "Integrated Study of Glacial Fluctuations and Its Impacts on Lakes in the Southeastern Tibetan Plateau", represent some of the current academic achievements in understanding glacial retreat and lake fluctuations in the southeastern Tibetan Plateau. These results will not only deepen our understanding of glacial fluctuations in the southeastern Tibetan Plateau, but also help formulate more quantitative approaches to assessing the influences of glacial fluctuations on lakes in the region.

email: tdyao@itpcas.ac.cn 